\title{
Victimization from Three Types of Intimate Partner Aggression and Mental Health Concomitants among Women in Pakistan
}

\author{
Taalia Khan \\ Åbo Akademi University, Finland \\ taalia.khan@abo.fi
}

\author{
Karin Österman \\ Åbo Akademi University, Finland \\ karin.osterman@abo.fi \\ (corresponding author)
}

\author{
Kaj Björkqvist \\ Åbo Akademi University, Finland \\ kaj.bjorkqvist@abo.fi
}

\begin{abstract}
The aim of the study was to compare associations between three types of female victimization from intimate partner aggression (IPA) and their mental health concomitants. A questionnaire was completed by 569 relatively well-educated women in Pakistan $(97.3 \%$ had at least a Bachelor's degree). The mean age was 31.4 years (SD 9.I), and the age range was between 18 and 70 years. The questionnaire included scales for measuring victimization from physical aggression, verbal aggression, and indirect aggressive social manipulation perpetrated by the husband against the wife, and four subscales from the Brief Symptom Inventory (BSI): depression, anxiety, obsessive compulsive symptoms, and somatization. Victimization from verbal aggression was the most common type, followed by indirect aggression, while physical aggression was the least common. All three types of IPA were significantly associated with all four BSI subscales and most strongly with indirect aggression, while physical aggression showed the weakest associations.
\end{abstract}

Keywords: Intimate partner aggression, physical, verbal, indirect, mental health, Pakistan

Received 19 July 2019/Accepted 10 September 2019 @JEHCP All rights reserved

\section{Introduction}

The aim of the study was to compare associations between victimization from three types of intimate partner aggression and psychological distress in a sample of Pakistani women. The choice of the word 'aggression' instead of 'violence' is here deliberate, since aggression is a wider concept than violence, with the latter being a subset of the former. All violence is aggression, but not all aggressive acts are violent. If aggression is seen as intentional harmdoing, then the harm aimed at in violent behavior is physical rather than psychological. Accordingly, the term intimate partner aggression (IPA), is preferred rather than the more 
commonly used intimate partner violence (IPV). However, the term IPV will be used whenever it this has been used in the cited articles. In the current study, three types of IPA were measured, namely physical, verbal, and indirect social manipulation.

A review of the prevalence of physical and/or sexual IPV against women in 81 countries has shown that $30.0 \%$ to $32.2 \%$ of women had been victimized during their lifetime (Devries et al., 2013). In South Asia, the rates of domestic aggression are higher than in other regions of the world (Kalokhe et al., 2017). The WHO estimate of the lifetime prevalence of domestic violence in South-East Asia is $37.7 \%$, which is higher than the regional estimates for Europe, the Americas, and the Western Pacific (WHO, 2013). A study from Bangladesh has shown that $42.7 \%$ of women were verbally abused, and $34 \%$ were psychologically abused by their husband (Ullah \& Parvin, 20I5).

Physical and Mental Health Concomitants of Intimate Partner Violence

IPV has been found to be associated with both physical and psychological problems. A significant association has also been found between victimization from psychological and physical intimate partner aggression (Pico-Alfonso, 2005). Physical problems include physical injury, sexually-transmitted diseases, gastrointestinal problems, and chronic pain (Campbell, 2002). Abused women have been found to have a $50 \%$ to $70 \%$ increase in gynecological, central nervous system, and stress-related problems (Campbell et al., 2002) as well as poor physical health, and chronic disease (Coker et al., 2002). In a review of IPV as a risk factor for mental health problems, it was concluded that IPV increases the risk for mental disorders in women (Golding, 1999). Several studies have found associations between IPV and depression (Campbell, 2002; Coker et al., 2002; Devries et al., 2013; Stein \& Kennedy, 200I), mental illness (Coker et al., 2002), and PTSD (Campbell, 2002; Stein \& Kennedy, $200 \mathrm{I})$. In a study from India, it was found that four in 10 women had suffered from domestic violence during their lifetime, which had led to mental health problems (Kalokhe et al., 2017). Victimization from physical IPV has also been found to be associated with substance abuse (Coker et al., 2002) and suicidal behaviour (Devries et al., 20I3). IPV is globally a leading cause of death by homicide in women (Stöckl et al., 20I3). 
Indirect and Psychological Aggression versus Physical Aggression

A few studies have shown that psychological/emotional aggression can in some samples even be more detrimental than physical aggression. In a study where psychological aggression was operationalized to include threats, isolation of the victim, and humiliation, it was found that the psychological component was the main contributor for the development of post traumatic stress disorder (Pico-Alfonso, 2005). In another study, it was found that victimization from psychological intimate partner aggression was as detrimental as victimization from physical aggression on all concomitants except for suicidality (PicoAlfonso et al., 2006). It has also been shown that victimization from psychological intimate partner aggression was more strongly associated with negative health outcomes than physical aggression (Coker et al., 2002). When the relationship between emotional abuse and physical abuse was subjectively assessed, psychological abuse had a greater adverse effect than physical abuse (Follingstad, Rutledge, Berg, Hause, \& Polek, 1990).

There are similarities between the concepts psychological/emotional aggression and indirect aggressive social manipulation. Items measuring indirect aggression have by some researchers been included in scales measuring psychological/emotional aggression. The difference between the concepts lies, however, in the fact that psychological/emotional aggression can be both direct and indirect. Due to this, in the present study, the concept of indirect aggressive social manipulation has been adopted. Indirect aggressive social manipulation in intimate partner relations differs from direct forms of physical and verbal aggression by being more subtle and manipulative and is often carried out behind the back of the partner. Typical indirect behaviours are e.g. to try to influence someone, such as children or relatives, to dislike the partner, to ridicule the partner in her/his absence, or to try to exclude the partner from social situations. Indirect IPA has previously been studied in South Sudan (Ndoromo, Österman, \& Björkqvist, 2017; Ndoromo, Österman, \& Björkqvist, 2018), in Ghana (Darko, Björkqvist, \& Österman, 2019), and in Finland and Mexico (Österman, Toldos, \& Björkqvist, 20।4). 
The Cultural Context of the Study

In Pakistan, the prevalent male dominated feudal culture is considered to be the main cause of gender inequality (Taga, 2012). Although Islam emphasizes gender equality, Pakistan remains severely engulfed in inequality (ibid.). Since birth, women are considered subordinate to men, be it in the realm of physical health, education, politics, or the labor market (Nasrullah, Zakar, \& Zakar, 20I4; Taga, 20I2). Early marriages make women vulnerable to societal pressure, since it leads to lack of education and social freedom. It has been found that early marriages, especially child marriages, are linked to domestic aggression (Nasrullah et al., 2014). Moreover, it was also shown that child marriages had long term negative effects on both the emotional and the physical health of the women. The divorce rate is very low in Pakistan since divorce is considered a stigma in most social classes (Ali, 201I); therefore, domestic aggression and conflicts are commonly considered a private matter. In 1998, there were 282 reported cases of burning of women connected to domestic aggression in Pakistan; of these women, $65 \%$ died due to the severity of their burns (Ali \& Gavino, 2008).

\section{Laws Concerning Domestic Aggression in Pakistan}

In Pakistan, state laws follow Shariah laws, and they are intended to protect the rights of women against domestic aggression; yet the laws are not applied to the fullest for political and societal reasons (Pakeeza, 20I5). The Pakistan Penal Court does not cover the whole spectrum of domestic aggression against women, but focuses on only a few issues, like miscarriages, and the abandonment of prepubescent children. Under the Domestic Violence Prevention and Protection Act (Act of the Legislature of Sindh, 2013), all types of physical, psychological, and gender-based harm directed at minors in the domestic environment are considered as acts of domestic violence. Despite efforts to legally banish violence against women, violations continue to take place (Pakeeza, 2015).

\section{Prevalence of Domestic Aggression in Pakistan}

Even though domestic aggression is common in Pakistan, there is no proper record of it (Rabbani, Qureshi, \& Rizvi, 2008), and the number of studies conducted on the issue is relatively low (Ali, Naylor, Croot, \& O'Cathain, 20I5). It has been estimated that between $30 \%$ to $79 \%$ of all cases of IPV in Pakistan are reported to the authorities, but action is taken 
only in a handful of them (Khan, Ali, \& Khuwaja, 2009). In a study on a sample of I50 Pakistani women, $34 \%$ were found to have sometimes been physically abused (Fikree \& Bhatti, 1999).

In a study on domestic violence against wives and working women in the city of Bahawalpur, $90 \%$ of the women reported that they had been victimised by a family member; the perpetrators were usually the husband, the father or the brother (Haq, 2017). Besides more traditional forms of domestic violence, cases of kidnapping, murder, rape, honour killing, acid throwing or bride burning have been reported (Ashraf \& Abrar-ul-Haq, 2017).

A study in urban areas of Karachi assessed the level of physical, sexual, and psychological IPV. The prevalence of lifetime physical IPV was $57.6 \%$, the prevalence of lifetime sexual abuse was $54.5 \%$, and of lifetime psychological abuse it was $83.6 \%$ (Ali, Asad, Mogren, \& Krantz, 20II). Poor socioeconomic status contributed to psychological, sexual, and physical abuse. Moreover, statistics show that a low level of education of the husband is a major risk factor for IPV (Khan, et al., 2009).

A study examined the inter-generational cycle of violence and the predictors for perpetration of physical abuse among Pakistani males (Fikree, Razzak, \& Durocher, 2005). The lifetime prevalence of the perpetration of intimate partner physical abuse was $49.4 \%$. Of males, $65 \%$ had, as children, witnessed when their mother was beaten, and $46.0 \%$ of the males accepted the idea that a man has the right to hit his wife.

A systematic review was made of 21 quantitative studies on IPV in Pakistan, of these I5 were conducted in different hospital environments (Ali et al., 20I5). Four different forms of IPV were identified in the studies: verbal, emotional, physical, sexual, and economic. It was concluded that studies on physical violence were the most common types of studies although other forms of IPV such as verbal, psychological, sexual, and economical were also investigated. Health effects, predictors, and reasons for different types of IPV were also reported. In another review $60 \%$ of the respondents reported that financial constraints were the main reason for IPV, while $15.3 \%$ reported that the joint family system was the prime issue (Khan et al., 2009). 
IPV has been reported to occur during 3-13\% of pregnancies in the world, leading to injuries and health risks for both mothers and infants (Campbell, 2002). In a study from Pakistan it was shown that $15 \%$ of the female respondents were abused while being pregnant (Fikree\& Bhatti, 1999). Another study, made in Karachi showed that $44 \%$ of the pregnant women in the sample had been physically or emotionally abused; however, social support diminished the abuse (Farid, Saleem, Karim, \& Hatcher, 2008).

\section{Mental Health Concomitants of Intimate Partner Aggression in Pakistan}

Several studies conducted in Pakistan has linked IPA to serious mental health problems. It has been found that domestic violence was positively associated with psychiatric distress and low self-esteem (Naeem, Irfan, Zaidi, Kingdon, \&Ayub, 2008). In another study, it was found that the self-esteem of psychologically and physically abused women in Pakistan was lower than for women who were not abused (Tariq, 2013). Anxiety and depression have also been found to prevail in $72 \%$ of a sample of abused Pakistani women (Fikree \& Bhatti, 1999). Furthermore, in a study from Lahore it has been demonstrated that victimization from physical and verbal aggression perpetrated by the husband had significant associations with psychiatric disorders of the wife (Ayub et al., 2009). In a study on married couples conducted in urban Karachi, it was shown that women who were victimized from domestic violence by the husband had poorer mental health than other women (Ali, Mogren, \& Krantz, 2013). Feelings of worthlessness were 12.6 times higher in victims of psychological aggression. Suicidal thoughts were 4.4 times more frequent in victims of physical and sexual violence, and 5.2 times more frequent in victims of psychological violence, compared to nonvictimized subjects. Victimized women also experienced higher rates of poor general health, problems with performing everyday activities, extreme memory or concentration problems, difficulties in decision making, and loss of interest in things they previously had enjoyed (Ali et al., 2013). The majority of a sample of suicidal married female patients in Pakistan reported that the main problem for them was IPA (80\%) and conflicts with in-laws (43\%) (Niaz, 1994). 
Originality of the Study

The number of studies conducted on IPA in Pakistan is relatively low (Ali, Nayloretal., 2015). The present study is aimed at adding to the research on IPA in Pakistan. Outof 21 previous quantitative studies, 15 were conducted in hospital environments (Ali etal., 20I5), while the present study includes respondents who were not hospitalized. Studies on physical violence have so far been the most common types of studies in Pakistan (Ali etal., 20I5), but the present study includes also measurements for victimization from in direct aggressive social manipulation which have not previously been reported in studies conducted in Pakistan.

\section{Method}

Respondents

A questionnaire was completed by 569 women in Pakistan. The mean age was 31.4 years (SD 9.1), and the age range was between 18 and 70 years. Of the respondents, $96.7 \%(550)$ were married, $2.3 \%$ divorced (I3), $0.9 \%$ widowed (5), and $0.2 \%$ (I) separated. Eighty-seven were pregnant, and 19 did not know whether they were pregnant or not. Two-point seven percent had a high school education or less, $45.4 \%$ had a Bachelors' level, and $51.9 \%$ a Masters' level of education or higher; the last group included 29 female medical doctors.

\section{Instrument}

A questionnaire was constructed in order to investigate female victimization from domestic aggression perpetrated by the husband, and its psychological concomitants. The following types of aggressive behavior perpetrated against the wife were measured: physical aggression, verbal aggression, and indirect aggressive social manipulation. Verbal and physical aggression were measured with the Direct Indirect Aggression Scale for Adults (Österman \& Björkqvist, 2009). Two items (bit, scratch) were removed since they did not fit in with a husband's behaviors. Items specifically suited for Pakistan were added (see below). The items in the scale measuring aggressive indirect social manipulation were all new and created to fit in with the culture in Pakistan. All items of the scales started with the question: "How often has your husband done the following?" Responses were given on a five-point scale $(0=$ never, $\mathrm{I}=$ seldom, 2 = sometimes, 3 = often, 4 = very often). 
Single items and Cronbach's alphas for the scales are presented below. Items with an asterisk were not from the original scales but were added to them. Physical aggression included I 3 items $(\alpha=.95)$ : "My husband has ...": hit me, locked me in, locked me out, shoved me, spit at me, thrown objects in anger, damaged something that was mine, kicked me*, tripped me when I was passing by*, pushed me back in order to prevent me from standing in front of him in different situations*, pulled my hair*, twisted my arm*, and intentionally burnt me with a cigarette*. Verbal aggression included 8 items $(\alpha=.91)$ : "My husband has ..." yelled at me, quarreled with me, purposely said nasty or hurting things to me about my appearance, called me bad names, interrupted me when I was talking, angrily nagged at me, criticized my family and friends*, and teased me*. Indirect Aggressive Social Manipulation included I 2 items $(\alpha=.96)$ : "My husband has ..." spoken badly about me to someone else, tried to influence someone, such as children, relatives, or servants, to dislike me, ridiculed me in my absence, tried to exclude me from social situations, tried to make me feel guilty, made socially fun of my intellect*, made negative comparisons between me and his sisters andlor mother*, regarded me as being lower than his family*, used social media and tagged in humiliating quotes and pictures of me*, gossiped to others about my family and upbringing*, plotted revenge against me in my absence*, and told false stories about me*.

The psychological status of the wife was measured with four standardized subscales, anxiety, depression, obsessive compulsive symptoms, and somatization, from the Brief Symptom Inventory (Derogatis \& Melisaratos, 1983). Responses were given on a five-point scale (0 = not at all, I = a little, 2 = moderately, 3 = much, 4 = very much).

\section{Procedure}

The data were collected with an online questionnaire during a period of two and a half months in 2017. Respondents were a convenience sample of women from three cities in Pakistan: the capital Islamabad, and the two provincial capitals Lahore and Karachi.

\section{Ethical Considerations}

The study adheres to the principles concerning human research ethics of the Declaration of Helsinki (World Medical Association, 2013), guidelines for the responsible conduct of research of the Finnish Advisory Board on Research Integrity (20I2), and the general data protection regulation of the European Union (European Commission, 2016). 


\section{Results}

Victimization from Three Types of Intimate Partner Aggression

Verbal aggression was the most commonly type of aggression perpetrated by the husbands (58\% of the total victimization scores), followed by indirect aggression (27\%), and physical aggression was the least common $(15 \%)\left[F_{(2,567)}=335.69, p<.00 \mathrm{I}, \eta_{p}{ }^{2}=0.542\right]$ (Fig. I).

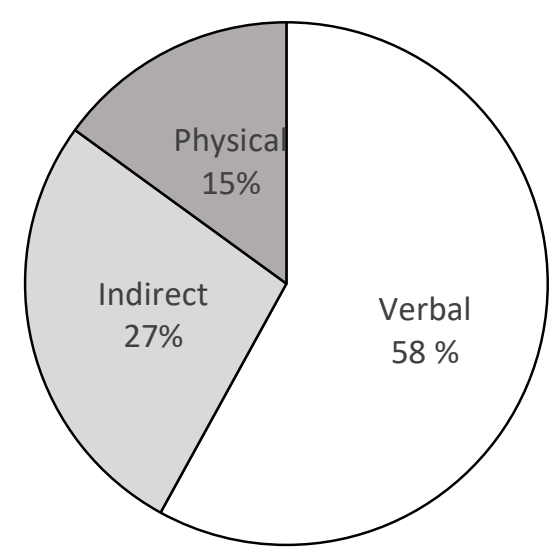

Figure I. Proportional distribution of the total victimization scores from three types of intimate partner aggression $(N$ $=569$ ).

The mean value was 0.23 (SD 0.54) for physical aggression, 0.90 (SD 0.85) for verbal aggression, and 0.43 (SD 0.75) for indirect aggression. The distribution of victimization scores is presented in Table I. The three types of victimization all correlated positively with all others at the $p<.00$ I-level, the correlational coefficients were all $>.67$.

The most common single behaviors of verbal aggression were quarreled with me, interrupted me when I was talking, and yelled at me. For indirect aggression, the most common single items were tried to make me feel guilty, made a negative comparison between me and his sisters and/or mother, and made socially fun of my intellect. For physical aggression, the most common behaviors were has thrown objects in anger, damaged something that was mine, and pushed me back in order to prevent me from standing in front of him in different situations. 
Table I

The Distribution of Scores for Victimization from Three Types of IPA

Measured by Composite Scales $(N=569)$

Percentual Distribution

\begin{tabular}{lcccccc} 
Victimization from & 0 & $0.1-0.9$ & $1-1.9$ & $2-2.9$ & $3-3.9$ & 4 \\
& Never & & & & & Very often \\
\hline Physical Aggression & $61.6 \%$ & $30.7 \%$ & $6.3 \%$ & $0.2 \%$ & $0.7 \%$ & $0.5 \%$ \\
Verbal Aggression & $10.9 \%$ & $54.1 \%$ & $25.0 \%$ & $5.8 \%$ & $2.2 \%$ & $2.0 \%$ \\
Indirect Aggression & $42.5 \%$ & $41.6 \%$ & $10.5 \%$ & $2.3 \%$ & $2.2 \%$ & $0.9 \%$ \\
\hline Note. For single items: 0 = never, I= seldom, 2 = sometimes, 3 = often, 4 = very often
\end{tabular}

A multivariate analysis of variance (MANOVA) revealed that there were no significant differences in victimization between pregnant and non-pregnant women. Accordingly, pregnant respondents were equally much victimized from all three types of IPA as nonpregnant ones.

The age of the respondents did not correlate with any of the three types of victimization. Neither was there a difference in degree of victimization between respondents at different educational levels.

Mental Health Concomitants of Victimization from Three Types of Intimate Partner Aggression The respondents were divided into two groups, one with respondents who had experienced more than the mean of physical victimization (high), and one with less than average victimization from physical aggression (low). The same procedure was followed for verbal and indirect aggression. Three separate multivariate analyses of variance (MANOVA) were then conducted, one for each type of victimization, with the three types of victimization as independent variables and four psychological concomitants as dependent variables. All three multivariate analyses were significant (Tables 2-4).

The univariate analyses showed that women who had been more than average victimized from physical aggression scored significantly higher on anxiety, depression, obsessive 
compulsive symptoms, and somatization than women who had been less victimized (Table 2). For victimization from verbal aggression (Table 3) and indirect aggression (Table 4) the same results were obtained. Mean values for concomitants of indirect aggression are presented in Fig. 2. The mean values for concomitants related to physical and verbal victimization followed the same pattern as for indirect victimization.

Table 2

Results of a Multivariate Analysis of Variance (MANOVA) with High vs. Low Victimization from Physical Intimate Partner Aggression as Independent Variable, and Four Psychological Concomitant as Dependent Variables $(N=569)$.

\begin{tabular}{lrccc}
\hline & $F$ & $d f$ & $p<$ & $\eta_{p}{ }^{2}$ \\
\hline Effect of High/Low Victimization & & & & \\
Multivariate analysis & 36.64 & 4,564 & .001 & .206 \\
Univariate analyses & & & & \\
$\quad$ Anxiety & 125.17 & $\mathrm{I}, 567$ & .001 & .181 \\
Depression & 120.58 & “ & .001 & .175 \\
Obsessive compulsive symptoms & 87.83 & “ & .001 & .134 \\
Somatization & 134.46 & “ & .001 & .192 \\
\hline
\end{tabular}

Table 3

Results of a Multivariate Analysis of Variance (MANOVA) with High vs. Low Victimization from Verbal Intimate Partner Aggression as Independent Variable, and Four Psychological Concomitant as Dependent Variables $(N=569)$.

\begin{tabular}{lcccc}
\hline & $F$ & $d f$ & $p<$ & $\eta_{p}{ }^{2}$ \\
\hline $\begin{array}{l}\text { Effect of High/Low Victimization } \\
\text { Multivariate analysis }\end{array}$ & 30.75 & 4,564 & .001 & .179 \\
Univariate analyses & & & & \\
Anxiety & 114.93 & 1,567 & .001 & .169 \\
Depression & $110.4 \mathrm{I}$ & “ & .001 & .163 \\
Obsessive compulsive symptoms & 100.72 & “ & .001 & .151 \\
Somatization & 93.66 & “ & .001 & .142 \\
\hline
\end{tabular}


Table 4

Results of a Multivariate Analysis of Variance (MANOVA) with High vs. Low Victimization from Indirect Aggression by an Intimate Partner as Independent Variable, and Four Psychological Concomitant as Dependent Variables $(N=569)$.

\begin{tabular}{lcccc}
\hline & $F$ & $d f$ & $p<$ & $\eta_{p}{ }^{2}$ \\
\hline $\begin{array}{l}\text { Effect of High/Low Victimization } \\
\text { Multivariate analysis }\end{array}$ & 53.95 & 4,564 & .001 & .277 \\
Univariate analyses & & & & \\
$\quad$ Anxiety & 203.46 & $\mathrm{I}, 567$ & .001 & .264 \\
Depression & 182.23 & “ & .001 & .243 \\
$\quad$ Obsessive compulsive symptoms & 146.90 & “ & .001 & .206 \\
Somatization & 181.55 & “ & .001 & .243 \\
\hline
\end{tabular}

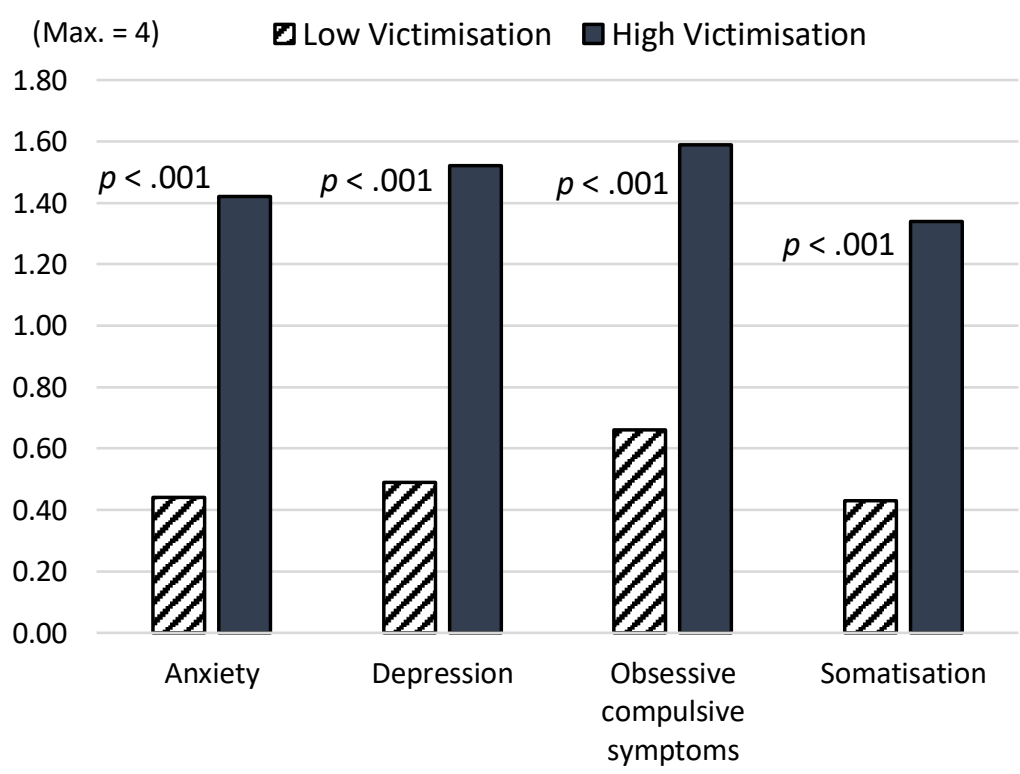

Figure 2. Mean values of psychological concomitants for women who had been more than average, and less than average victimised from indirect intimate partner aggression $(N=569)$. 
Comparisons of the Associations between Victimization from Three Types of IPA and Mental Health Concomitants

All three types of victimization from intimate partner aggression, physical, verbal and indirect aggression, correlated significantly with the four psychological concomitants anxiety, depression, obsessive compulsive symptoms, and somatization. For indirect aggression, the correlational coefficients were all above .50 (Table 5).

Table 5

Correlations between Victimization from Intimate Partner Aggression and Four Psychological Concomitants $(N=569)$.

\begin{tabular}{|c|c|c|c|c|}
\hline \multirow[t]{2}{*}{$\begin{array}{l}\text { Psychological } \\
\text { Concomitants }\end{array}$} & \multicolumn{3}{|c|}{$\begin{array}{c}\text { Victimization from Intimate Partner } \\
\text { Aggression }\end{array}$} & \multirow{2}{*}{$\begin{array}{l}\text { Significant } \\
\text { differences } \\
\text { between } r s \\
\text { see the tex }\end{array}$} \\
\hline & $\begin{array}{l}\text { Physical } \\
\text { A }\end{array}$ & $\begin{array}{l}\text { Verbal } \\
\text { B }\end{array}$ & Indirect & \\
\hline Anxiety & $.41 * * *$ & $.50 * * *$ & $.57 * * *$ & $A<C$ \\
\hline Depression & $.37 * * *$ & $.48 * * *$ & $.54 * * *$ & $\begin{array}{l}A<B \\
A<C\end{array}$ \\
\hline Obsessive Compulsive Symptoms & $.33 * * *$ & $.48 * * *$ & $.51 * * *$ & $\begin{array}{l}A<B \\
A<C\end{array}$ \\
\hline Somatization & $.41 * * *$ & $.46 * * *$ & $.55 * * *$ & $A<C$ \\
\hline
\end{tabular}

In order to compare the correlational coefficients between the three types of victimization and the four psychological concomitants, Fisher's $r$ to $z$ transformation was used: $z=-\left(z_{r}-\right.$ $\left.z_{r 2}\right) / \sqrt{(1 /(n 1-3)+1 /(n 2-3))}$ in which $z_{r}=1 / 2 \ln ((I+r) /(I-r))$. A $z$-value $\geq 1.96$ indicates $p<.05$. It was found that the correlational coefficients between indirect aggression and the four psychological concomitants $(r=.51-.57)$ were all significantly larger than the correlations between victimizations from physical aggression and the same concomitants $(r=$ $.33-.4 \mathrm{I})(z \geq 3.07$ for all, $p<.05)$ (Table 5). The correlational coefficients between victimization from verbal aggression and depression and obsessive compulsive symptoms (both $r=.48$ ) were also both significantly higher than the correlations between victimization from physical aggression and the same two concomitants $(r=.33,37)(z>2.27$ for both, $p<$ .05). There was no significant difference between the correlational coefficients for physical and verbal aggression with anxiety or somatization. For depression, the correlational coefficient was significantly lower with physical aggression (.37) than with verbal aggression 
(.48). The same was the case for obsessive compulsive symptoms; the correlational coefficient was significantly lower with victimization from physical (.33) than with verbal aggression (.48). No significant differences were found between the correlational coefficients for verbal aggression and indirect aggression with any of the psychological concomitants.

Four linear multiple regression analyses (method Enter) were conducted with the four types of IPA predicting anxiety, depression, obsessive compulsive symptoms, and somatisation (Table 6). Indirect aggression predicted all four psychological concomitants, while verbal aggression predicted all but somatisation. Physical aggression predicted only obsessive compulsive symptoms, however negatively. The $\beta$-values were highest for indirect aggression (between .42 and .49); for the other types of aggression, they were below .26.

Table 6

Results of Four Linear Multiple Regression Analyses with Three Types of IPA Predicting Four Psychological Concomitants ( $N=569)$

\begin{tabular}{llllllll}
\hline Predictors and Predicted Variables & $\beta$ & $p \leq$ & $R$ & $R^{2}$ & $F$ & $p<$ & $d f$ \\
\hline Predicted: Anxiety & & & .58 & .34 & 96.91 & .001 & 3,565 \\
$\quad$ Physical Aggression & -.06 & $n s$ & & & & & \\
$\quad$ Verbal Aggression & .18 & .001 & & & & & \\
$\quad$ Indirect Aggression & .49 & .001 & & & & & \\
Predicted: Depression & & & .55 & .31 & 83.39 & .001 & 3,565 \\
$\quad$ Physical Aggression & -.10 & .069 & & & & & \\
$\quad$ Verbal Aggression & .19 & .001 & & & & & \\
$\quad$ Indirect Aggression & .47 & .001 & & & & & \\
Predicted: Obsessive Compulsive Symptoms & & & .54 & .29 & 75.60 & .001 & 3,565 \\
$\quad$ Physical Aggression & -.15 & .007 & & & & & \\
$\quad$ Verbal Aggression & .25 & .001 & & & & & \\
$\quad$ Indirect Aggression & .42 & .001 & & & & & \\
Predicted: Somatisation & & & .55 & .31 & 83.32 & .001 & 3,565 \\
$\quad$ Physical Aggression & -.02 & $n s$ & & & & & \\
$\quad$ Verbal Aggression & .10 & .081 & & & & & \\
$\quad$ Indirect Aggression & .49 & .001 & & & & & \\
\hline
\end{tabular}




\section{Discussion}

The aim of the study was to investigate associations between three types of victimization from IPA and mental health concomitants. The most common type of victimization was from verbal aggression which constituted $58 \%$ of the total victimization. The second most common type was from indirect aggression, which constituted $27 \%$ of the total victimization. Victimization from physical aggression was the least common type, which constituted only I5\% of all victimization. A systematic review of studies on IPV in Pakistan (Ali et al., 20I5) has concluded that studies on physical violence have so far been the most common ones. Therefore, the findings from the present study indicate that since other forms of victimization apart from physical ones might be more frequent, these should also be studied. In comparison with another study on IPA in Pakistan (Ali et al., 20II) the mean values for victimization were relatively low in the current sample. On a scale from zero to four, the summed scores for all types of victimization remained below I (= seldom). The score for physical aggression, 0.23, was the lowest one. A study from Pakistan has previously shown that low levels of education of the husband are a risk factor for intimate partner violence (Khan, et al., 2009). Thus, the overall low scores might be explained by the relatively high educational level of the respondents in the sample.

It is notable that pregnant respondents were equally much victimized as non-pregnant ones. This finding corroborates another study from Pakistan, where 15\% of the pregnant females were found to have been abused (Fikree \& Bhatti, 1999), and also a third study from Pakistan according to which $44 \%$ of the pregnant participants had been both physically and emotionally abused (Farid et al., 2008).

Women who had been more than average victimized from any of the three forms of aggression - physical, verbal, or indirect - scored significantly higher on anxiety, depression, obsessive compulsive symptoms, and somatization than those who had been less victimised. The findings are in line with those of several previous studies from Western countries (Campbell, 2002; Coker et al., 2002; Devries et al., 2013; Golding, 1999; Stein \& Kennedy, 200I). Also, in Pakistan, several studies have linked domestic violence to psychological distress (Ali, et al., 2013; Ayub et al., 2009; Naeem et al., 2008; Niaz, 1994; Tariq, 2013). 
Furthermore, it was found that the correlational coefficients between victimizations from physical aggression and the four psychological concomitants were all significantly lower than the correlations between victimization from indirect aggression and the same concomitants. For depression and obsessive compulsive symptoms, the correlations were also lower for physical aggression than for verbal aggression. Indirect aggression usually aims at psychological rather than physical harm. In the present study, all four symptoms of psychological distress showed the highest association with victimization from indirect aggression ( $\beta$-values varied between .42 and 49), and the lowest association with victimization from physical aggression. This is in line with previous studies, in which psychological/emotional aggression has been shown to be equally detrimental as physical victimization (Pico-Alfonso et al., 2006), or even more detrimental (Coker et al., 2002; Follingstad, Rutledge, Berg, Hause, \& Polek, 1990; Pico-Alfonso, 2005).

In this well-educated Pakistani sample, with relatively low scores of victimization from IPA, the strongest predictor for mental health problems was indirect aggressive social manipulation, while victimization from physical aggression did not predict mental health problems. Low levels of victimization in general, and especially of physical aggression, might contribute to these results. However, victimization from IPA and psychological distress associated with it appears to be a serious problem in Pakistan, as strong associations were found even in this well-educated sample. So far, a limited number of studies on IPA have been conducted in Pakistan, and there is a dire need to educate both women and men about the issue.

\section{Conclusion}

The most common types of victimization was found to be from verbal and indirect aggression, while physical aggression was the least common type. Furthermore, psychological distress showed the highest association within direct aggression and the lowest with physical aggression.

The low mean values for victimization in the current sample of well-educated respondents suggest that education plays a crucial part. It is noted that the strongest predictor for mental 
health problems in this sample was indirect aggressive social manipulation, while victimization from physical aggression did not predict mental health problems.

Studies on physical violence have so far been the most commonones in Pakistan (Ali et al., 2015). Future studies would benef it from including also other forms of aggression besides physical forms of IPA. Groups with different levels of education are also needed to be included in studies on IPA in Pakistan.

\section{Acknowledgement}

The study was supported by a grant from Högskolestiftelsen i Österbotten, Finland.

\section{References}

Act of the Legislature of Sindh. (2013). The domestic violence (prevention and protection) act, Sindh act no. XX. Provincial Assembly of Sindh, Karachi, Pakistan. http://www.pas.gov.pk/index.php/acts/details/en/I9/2I5

Ali, P. A., \& Gavino, M. I. B. (2008). Violence against women in Pakistan: A Framework for Analysis. Journal of Pakistan Medical Association, 58, 198-203.

Ali, P. A., Naylor, P. B., Croot, E., \& O'Cathain, A. (20I5). Intimate partner violence in Pakistan: A systematic review. Trauma, Violence, \& Abuse, 16, 299-3I5.

Ali, T. S. (20I I). Living with violence in the home: Exposure and experiences among married women, residing in urban Karachi, Pakistan. Stockholm, Sweden: Karolinska Institutet, Department of Public Health Sciences.

Ali, T. S., Asad, N., Mogren, I., \& Krantz, G. (20I I). Intimate partner violence in urban Pakistan: Prevalence, frequency, and risk factors. International Journal of Women's Health, 16, 105-II5.

Ali, T. S., Mogren, I., \& Krantz, G. (20I3). Intimate partner violence and mental health effects: A population-based study among married women in Karachi, Pakistan. International Journal of Behavioral Medicine, 20, I31-139.

Ashraf, S., \& Abrar-ul-Haq, M. (2017). Domestic violence against women: Empirical evidence from Pakistan. Pertanika Journal of Social Sciences \& Humanities, 25, |40|-|4|8.

Ayub, M., Irfan, M., Nasr, T., Lutufullah, M., Kingdon, D., \& Naeem, F. (2009). Psychiatric morbidity and domestic violence: A survey of married women in Lahore. Social Psychiatry and Psychiatric Epidemiology, 44, 953-960. doi:10.1007/s00 I27-009-00 I6-6 
Campbell, J. C. (2002). Health consequences of intimate partner violence. The Lancet, 359, $|33|-1336$.

Campbell, J., Jones, A. S., Dienemann, J., Kub, J., Schollenberger, J., O'campo, P., ... \& Wynne, C. (2002). Intimate partner violence and physical health consequences. Archives of Internal Medicine, I62, II57-II63.

Coker, A. L., Davis, K. E., Arias, I., Desai, S., Sanderson, M., Brandt, H. M., \& Smith, P. H. (2002). Physical and mental health effects of intimate partner violence for men and women. American Journal of Preventive Medicine, 23, 260-268. doi:10.1016/S0749. 3797(02)005 I4-7

Darko, G., Björkqvist, K., \& Österman, K. (2019). Low intensity intimate partner aggression in Ghana: Support for the revised gender symmetry theory in an African country. Aggressive Behavior, 45, 52-61.doi:10.1002/ab.21796

Derogatis, L. R., \& Melisaratos, N. (1983). The Brief Symptom Inventory: An Introductory Report. Psychological Medicine, 13, 595-605.

Devries, K. M., Mak, J. Y., Bacchus, L. J., Child, J. C., Falder, G., Petzold, M., ... \& Watts, C. H. (2013). Intimate partner violence and incident depressive symptoms and suicide attempts: A systematic review of longitudinal studies. PLoS Medicine, 10, el00I439.

European Commission (2016). Data protection. Rules for the protection of personal data inside and outside the EU.https://ec.europa.eu/info/law/law-topic/data-protection_en

Farid, M., Saleem, S., Karim, M. S., \& Hatcher, J. (2008). Spousal abuse during pregnancy in Karachi, Pakistan. International Journal of Gynecology and Obstetrics, I0I, I4I-45. doi:10.1016/j.ijgo.2007.11.015

Fikree, F. F., \& Bhatti, L. I. (1999). Domestic violence and health of Pakistani women. International Journal of Gynecology \& Obstetrics, 65, 195-20I.

Fikree, F. F., Razzak, I. A., \& Durocher, I. (2005). Attitudes of Pakistani men to domestic violence: A study from Karachi, Pakistan. Journal of Men's Health \& Gender, 2, 49-58.

Finnish Advisory Board on Research Integrity (2012). Responsible conduct of research and procedures for handling allegations of misconduct in Finland. Helsinki: Finnish Advisory Board on Research Integrity.

Follingstad, D. R., Rutledge, L. L., Berg, B. I., Hause, E. S., \&Polek, D. S. (1990). The role of emotional abuse in physically abusive relationships. Journal of Family Violence, 5 , 107-120.

Golding, J. M. (1999). Intimate partner violence as a risk factor for mental disorders: A metaanalysis. Journal of Family Violence, 14, 99-I 32.

Haq, A. U. (20I7). Domestic violence against women: Empirical evidence from Pakistan. Pertanika Journal of Social Science and Humanities, 25, I40 I-I4I8. 
Kalokhe, A., del Rio, C., Dunkle, K., Stephenson, R., Metheny, N., Paranjape, A., \& Sahay, S. (2017). Domestic violence against women in India: A systematic review of a decade of quantitative studies. Glob Public Health, 12, 498-513. doi:10.1080/I7441692.2015.1।119293

Khan, A. J., Ali, T. S., \& Khuwaja, A., K. (2009). Domestic violence amongst Pakistani women: An insight into literature. ISRA Medical Journal, I, 54-56.

Naeem, F., Irfan, M., Zaidi, Q. A., Kingdon, D., \& Ayub, M. (2008). Angry wives, abusive husbands: Relationship between domestic violence and psychosocial variables. Women's Health Issues, 18, 453-462.

Nasrullah, M., Zakar, R., \& Zakar, M. Z. (20I4). Child marriage and its association with controlling behaviors and spousal violence against adolescent and young women in Pakistan. Journal of Adolescent Health, 55, 804-809. doi.org/10.1016/j.jadohealth.2014.06.013

Ndoromo, O., Österman, K., \& Björkqvist, K. (20I7). Sex differences in victimization from low intensity intimate partner aggression in South Sudan. European Journal of Social Sciences Education and Research, I I, 2, I5-23. doi:I0.264I 7/ejser.v I Ii2.p I 5-23

Ndoromo, O., Österman, K., \& Björkqvist, K. (2018). Sex differences in perpetration of low intensity intimate partner aggression in South Sudan. European Journal of Interdisciplinary Studies, 10, 93-101. doi:10.264I7/ejis.v10il.p93-10I

Niaz, U. (1994). Human rights abuse in family. Journal of Pakistan Association of Women's Studies, 3, 33-4I.

Österman, K., \& Björkqvist, K. (2009). Direct Indirect Aggression Scales for Adults (DIAS-Adult). ÅboAkademi University, Finland

Österman, K., Toldos, M. P., \& Björkqvist, K. (20I4). Direct and indirect aggression in intimate relationships in Mexico and Finland. XXlth World Meeting of the International Society for Research on Aggression, Atlanta, GA, July 15-19. doi:

I0.13|40/RG.2.2.35573.17I22

Pakeeza, S. (2015). Domestic violence laws and practices in Pakistan. VFAST Transactions on Education and Social Sciences, 6, 17-20.

Pico-Alfonso, M. A. (2005). Psychological intimate partner violence: The major predictor of posttraumatic stress disorder in abused women. Neuroscience \&Biobehavioral Reviews, 29, I8I-193. doi:10.1016/j.neubiorev.2004.08.010

Pico-Alfonso, M. A., Garcia-Linares, M. I., Celda-Navarro, N., Blasco-Ros, C., Echeburúa, E., \& Martinez, M. (2006). The impact of physical, psychological, and sexual intimate male partner violence on women's mental health: depressive symptoms, posttraumatic stress disorder, state anxiety, and suicide. Journal of Women's Health, 15, 599-6II. doi:10.1089/jwh.2006.15.599 
Rabbani, F., Qureshi, F., \& Rizvi, N. (2008). Perspectives on domestic violence: Case study from Karachi, Pakistan. Eastern Mediterranean Health Journal, 14, 4I5-426.

Stein, M. B., \& Kennedy, C. (200I). Major depressive and post-traumatic stress disorder comorbidity in female victims of intimate partner violence. Journal of Affective Disorders, $66,133-138$.

Stöckl, H., Devries, K., Rotstein, A., Abrahams, N., Campbell, J., Watts, C., \& Moreno, C. G. (2013). The global prevalence of intimate partner homicide: A systematic review. The Lancet, 382(9895), 859-865.

Taga, A. A. (2012). Gender gap in Pakistan: A sociological analysis. Academic Research International, 2, I-8.

Tariq, Q. (20I3). Impact of intimate partner violence on self esteem of women in Pakistan. American Journal of Humanities and Social Sciences, I, 25-30.

Ullah, M. R., \& Parvin, S. (20I5). Socio-economic status of women influences of domestic violence: A sociological analysis at urban area in Bangladesh. International Journal Soc. Sci. Stud., 3, I49-I58. doi: I0.I I I |4/ijsss.v3i3.775

WHO, World Health Organization (20I3). Global and regional estimates of violence against women. Prevalence and health effects of intimate partner violence and non-partner sexual violence. Department of Reproductive Health and Research, London School of Hygiene and Tropical Medicine, and South African Medical Research Council. https://www.who.int/reproductivehealth/publications/violence/978924I564625/en/

World Medical Association (20/3). World Medical Association Declaration of Helsinki. Ethical principles for medical research involving human subjects. Bulletin of the World Health Organization, 79, 373-374. 